\title{
IMPACTO DA TRIBUTACIÓN AUTONÓMICA SOBRE EMISIÓNS. UNHA PERSPECTIVA MICROECONÓMICA
}

Jaime VALLES-GIMENEZ : jvalles@unizar.es Juan A. ROMÁN-ASO: juananromanaso@gmail.com Facultade de Economía e Empresa, Universidade de Zaragoza Gran Vía, 2 - 50005, Zaragoza

Resumo: O obxectivo deste traballo é analizar o impacto da tributación autonómica sobre emisións para dúas mostras de 100 instalacións industriais en España. A primeira está composta polos fluxos anuais de dióxido de carbono, namentres que a segunda recolle os de óxidos de nitróxeno e de azufre, as dúas para o período 2001-2011. A implementación da política fiscal debe estar orientada a internalizar o dano ambiental causado polas emisións. Porén, os resultados suxiren que a efectividade da tributación autonómica é moi limitada, debido entre outras causas, ao inadecuado deseño tributario. Ademais, avalíase o efecto doutros factores sobre a evolución da contaminación industrial, particularmente do sistema de intercambio de permisos.

Palabras chave: política ambiental, impostos rexionais, descentralización.

Abstract: The aim of this paper is to analyse the impact of the emissions regional taxes for two samples of 100 industrial plants in Spain. The first sample is composed of the annual flows of carbon dioxide emissions, while the second collects data about the nitrogen and sulphur oxides, over the period 2001- 2011. The implementation of the fiscal policy is to be addressed to internalize the environmental damage caused by emissions. However, our results suggest that the effectiveness of the regional taxes is very low, due the inappropriate tax design, among other causes. In addition, we evaluate the effect of other factors in the evolution of industrial pollution, particularly the allowance trading system. Keywords: environmental policy, regional taxes, decentralization.

JEL Classification: $\mathrm{H} 22$, $\mathrm{H} 23$

\section{1.- Introdución}

De acordo co concepto clásico de fallo do mercado, a contaminación industrial é un claro exemplo de externalidade negativa que ten lugar cando un axente económico non asume o custo total da súa actividade. Durante as últimas décadas, implementáronse diferentes tributos de carácter pigouviano destinados a corrixir o devandito fallo de mercado. O propósito da súa aplicación é xerar un aumento no custo marxinal privado que o equipare co custo marxinal social (Pigou, 1920). Como resultado, o novo equilibrio paretiano débese basear nun nivel de produción socialmente eficiente onde todos os custos asociados ao proceso produtivo sexan tidos en conta. Trátase, polo tanto, da internalización do fallo de mercado derivado da actividade contaminante.

Atendendo a Gago e Labandeira (1997), a tributación tamén pode estimular un incentivo potencial a longo prazo para a innovación e as novas tecnoloxías, o que se traduce nunha menor contaminación. Ademais, a política fiscal permite un aumento dos ingresos públicos e a posibilidade de reducir impostos directos simultaneamente, baixo a hipótese de neutralidade recadadora. Deste xeito, pódense acadar beneficios de tipo ambiental e económico (derivados da redución de impostos directos). Esta hipótese, denominada dobre dividendo, foi analizada frecuentemente pola literatura empírica e atopou un amplo apoio en distintas meta-análises, como as de Bosquet (2000), Rodríguez (2002), Gago et al. (2004) ou Patuelli et al. (2005), así como noutros estudos empíricos como os de Cardenete e Velázquez (2005) e Conefrey et al. (2008), para Andalucía e Irlanda, respectivamente.

A forma de fiscalizar as emisións pode ser directa ou indirecta. No primeiro caso, inclúense as emisións na base impoñible e págase en función do volume emitido. No 
segundo, os tributos aplícanse sobre actividades asociadas á xeración de emisións como a produción e o consumo de combustibles, a adquisición e utilización de vehículos, 0 consumo de electricidade e gas natural ou a xeración de residuos, entre outros (é moi habitual encontrar figuras tributarias deste tipo nalgúns países europeos como Holanda, Finlandia, Alemaña, Suecia, Dinamarca e Italia). Porén, o obxectivo principal do presente traballo é a análise da tributación autonómica sobre emisións que se encadra no primeiro grupo, por iso, imos facer referencia aos tributos europeos que teñen un vencello directo co fluxo de contaminación anual.

Neste punto, presentamos a estrutura do resto do traballo. A sección 2 ocúpase de revisar a literatura previa e presenta os tributos directos a nivel europeo e español. A parte metodolóxica inclúese na sección 3, ademais da información relevante sobre as variables dos modelos. Trala análise empírica, presentamos e analizamos os resultados máis importantes da investigación na sección 4. Para rematar, a última sección conclúe 0 documento e presenta algunhas implicacións políticas.

\section{2.- Tributación ambiental e emisións: revisión da literatura}

Antes de analizar as aportacións da literatura previa, é importante ter presente 0 panorama nacional e internacional en materia de tributación directa sobre as emisións. Así, se se revisa o contexto europeo, podemos destacar os impostos sobre o NOx, que se aplican nos países nórdicos; o imposto sobre as emisións de gases de efecto invernadoiro que exceden os límites establecidos no sistema europeo de intercambio en Finlandia; o imposto xeral sobre actividades contaminantes en Francia; ou os diferentes gravames sobre a contaminación na República Checa, Estonia, Eslovaquia, Hungría e Italia.

Como se observa na táboa 1, a intensidade na aplicación da política fiscal varía xeograficamente de forma notable. Estas diferenzas fanse visibles se comparamos os impostos que implementan os países nórdicos (Noruega, Dinamarca e Suecia) cos do este de Europa (Eslovaquia, Hungría ou a República Checa), o que implica que o compromiso da política no cumprimento dos obxectivos ambientais é notablemente superior no norte do continente.

Táboa 1: Impostos sobre emisións en Europa

\begin{tabular}{|l|l|c|c|}
\hline País & Denominación & $\begin{array}{c}\text { Base } \\
\text { liquidable }\end{array}$ & $\begin{array}{c}\text { Tipo de } \\
\text { gravame }\end{array}$ \\
\hline Eslovaquia & Taxa sobre a contaminación & $\mathrm{NOx}$ & 48.01 \\
\hline Estonia & Taxa sobre a contaminación & $\mathrm{NOx}$ & 2224.0 \\
\cline { 3 - 4 } & & $\mathrm{SO}_{2}$ & 2238.0 \\
\hline Dinamarca & Imposto sobre o NOx & $\mathrm{NOx}$ & 3470 \\
\hline Finlandia & Taxa por exceder os límites de GEI & $\mathrm{GEI}$ & 100.0 \\
\hline Francia & Imposto xeral sobre actividades contaminantes & $\mathrm{NOx}$ & 160.8 \\
\cline { 3 - 4 } & & $\mathrm{SOx}$ & 136.0 \\
\hline Hungría & Taxa sobre contaminación & $\mathrm{NOx}$ & 404.1 \\
\cline { 3 - 4 } & & $\mathrm{SOx}$ & 168.4 \\
\hline Italia & Imposto sobre o NOx e o SO2 & $\mathrm{NOx}$ & 209.0 \\
\hline Noruega & & $\mathrm{SO} 2$ & 106.0 \\
\hline $\begin{array}{l}\text { República } \\
\text { Checa }\end{array}$ & Taxa sobre a contaminación & $\mathrm{NOx}$ & 2220 \\
\hline Suecia & Imposto sobre o NOx & $\mathrm{NOx}_{2}$ & 42.35 \\
\hline
\end{tabular}

Fonte: elaboración propia a partir da base de datos: OECD/EEA database on instruments used for environmental policy and natural resources management. Datos en $€ /$ tonelada. Nota: En Suecia, o imposto só afecta ás plantas de produción de enerxía. En Finlandia, o tipo calcúlase en €/ tonelada de $\mathrm{CO}_{2}$ equivalente. 
Táboa 2: Impostos sobre emisións en España

\begin{tabular}{|c|c|c|c|c|c|c|}
\hline \multirow{2}{*}{$\begin{array}{c}\text { Comunidade } \\
\text { Autónoma }\end{array}$} & \multirow{2}{*}{$\begin{array}{c}\text { Denomi } \\
\text { nación }\end{array}$} & \multicolumn{5}{|c|}{ Tipo de gravame } \\
\hline & & NOx & SOx & $\mathrm{CO}_{2}$ & $\mathrm{COV}$ & $\mathrm{NH}_{3}$ \\
\hline $\begin{array}{l}\text { Andalucía } \\
\text { (2004) }\end{array}$ & $\begin{array}{l}\text { Imposto sobre } \\
\text { emisión de } \\
\text { gases á } \\
\text { atmosfera }\end{array}$ & $\begin{array}{l}0-1000: 50 \\
1000-3000: \\
80 \\
3000-4000: \\
100 \\
4000-5000: \\
120 \\
>5000: 140\end{array}$ & $\begin{array}{l}0-1500: \\
33,33 \\
1500-4500: \\
53,33 \\
4500-6000: \\
66,67 \\
6000-7500: \\
80,00 \\
>7500: \\
93,33\end{array}$ & $\begin{array}{l}\text { 0-1000000: } \\
0,05 \\
\text { 1000000- } \\
\text { 3000000: } 0,08 \\
\text { 3000000- } \\
4000000: 0,10 \\
4000000- \\
5000000: 0,12 \\
>5000000: \\
0,14\end{array}$ & & \\
\hline $\begin{array}{l}\text { Aragón } \\
\text { (2006) }\end{array}$ & $\begin{array}{l}\text { Imposto sobre } \\
\text { contaminación } \\
\text { atmosférica }\end{array}$ & $\begin{array}{l}0 \text { a 100: } 0 \\
>100: 50\end{array}$ & $\begin{array}{l}0 \text { a } 150: 0 \\
>150: 50\end{array}$ & 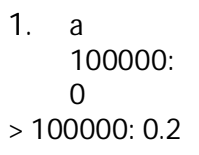 & & \\
\hline $\begin{array}{l}\text { Castela-A } \\
\text { Mancha } \\
\text { (2001) }\end{array}$ & $\begin{array}{l}\text { Imposto sobre } \\
\text { determinadas } \\
\text { actividades que } \\
\text { inciden no } \\
\text { Medio } \\
\text { Ambiente }\end{array}$ & $\begin{array}{l}0 \text { a } 500: 0 \\
501 \text { a } 5000: \\
51 \\
5001 \text { a } \\
10000: 90 \\
10001 \text { a } \\
15000: 120 \\
>15000: \\
150\end{array}$ & $\begin{array}{l}0 \text { a } 500: 0 \\
501 \text { a } 5000: \\
34 \\
5001 \text { a } \\
10000: 60 \\
10001 \text { a } \\
15000: 80 \\
>15000: \\
100\end{array}$ & & & \\
\hline $\begin{array}{l}\text { Galicia } \\
\text { (1996) }\end{array}$ & $\begin{array}{l}\text { Imposto sobre } \\
\text { a contami- } \\
\text { nación } \\
\text { atmosférica }\end{array}$ & $\begin{array}{l}0 \text { a } 1000: 0 \\
1000,01 \text { a } \\
40000: 33 \\
40000,01 \text { a } \\
80000: 36 \\
>80000: 42\end{array}$ & $\begin{array}{l}0 \text { a } 1000: 0 \\
1000,01 \text { a } \\
40000: 33 \\
40000,01 \text { a } \\
80000: 36 \\
>80000: 42\end{array}$ & & & \\
\hline $\begin{array}{l}\text { Murcia } \\
(2006)\end{array}$ & $\begin{array}{l}\text { Imposto } \\
\text { por emisións } \\
\text { de gases á } \\
\text { atmosfera } \\
\text { (substitúe } \\
\text { ao canon } \\
\text { do ano 1995) }\end{array}$ & $\begin{array}{l}0-1000: 50 \\
1000-3000: \\
80 \\
3000-4000: \\
100 \\
4000-5000: \\
120 \\
>5000: 140\end{array}$ & $\begin{array}{l}0-1500: \\
33,33 \\
1500-4500: \\
53,33 \\
4500-6000: \\
66,67 \\
6000-7500: \\
80,00 \\
>7500: \\
93,33\end{array}$ & & $\begin{array}{l}0-1000: \\
50 \\
1000- \\
3000: 80 \\
3000- \\
4000: \\
100 \\
4000- \\
5000: \\
120 \\
>5000: \\
140\end{array}$ & $\begin{array}{l}0-100: \\
50 \\
100- \\
300: 80 \\
300- \\
400: \\
100 \\
400- \\
500: \\
120 \\
>500: \\
140\end{array}$ \\
\hline
\end{tabular}

Fonte: elaboración propia a partir da lexislación autonómica. Datos en €/tonelada. Nota: En Andalucía e Murcia, a contaminación mídese en unidades contaminantes, sendo 1 Unidade Contaminante de $\mathrm{CO}_{2}=100.000$ toneladas; 1 Unidade Contaminante NOx $=100$ toneladas; 1 Unidade Contaminante SOx $=150$ toneladas; 1 Unidade Contaminante COV = 100 toneladas; 1 Unidade Contaminante $\mathrm{NH}_{3}=10$ toneladas. 
Asemade, é sorprendente a ausencia de tributación directa sobre o dióxido de carbono, sendo a devandita substancia, a máis emitida en todo o mundo. Isto débese fundamentalmente a que o control das súas emisións realízase a través da aplicación dun sistema de intercambio de permisos negociables entre as instalacións contaminantes europeas. O que se grava na maior parte dos tributos, son os óxidos de azufre ou nitróxeno, co fin de paliar os efectos da choiva ácida que representa un peligro considerable para a sustentabilidade ambiental ${ }^{1}$.

Porén, en España atopamos dúas autonomías (Andalucía e Aragón) que fiscalizan de forma directa a emisión de dióxido de carbono, o que representa indubidablemente un factor novidoso en materia de tributación ambiental europea. A táboa 2 amósanos 0 escenario fiscal español onde destacan tres feitos fundamentais; o reducido número de autonomías que implementaron un imposto destas características (só cinco), a limitada contía dos tipos de gravame, e os elevados mínimos exentos en Galicia, Castela-A Mancha e Aragón. Isto último restrinxe considerablemente o número de contribuíntes, e circunscribe o pago tributario ás empresas de gran tamaño ${ }^{2}$.

Porén, a principal peculiaridade é que a xurisdición encargada da súa xestión e recadación sexa a subcentral, namentres que no ámbito europeo ocúpase o goberno central, como se deduce da base de datos da $\mathrm{OCDE}^{3}$. A orixe desta diverxencia provén fundamentalmente, da configuración do sistema de financiamento autonómico, que non permite aos gobernos subcentrais gravar feitos impoñibles que se atopen fiscalizados pola administración central. Neste contexto e ante a inexistencia de tributación ambiental a nivel nacional, algúns gobernos autonómicos optaron por implementar figuras tributarias deste tipo 4 .

A asignación xurisdicional da tributación ambiental espertou interese na literatura académica dende as súas primeiras aplicacións. É conveniente destacar que existe certo consenso sobre que o factor máis relevante é o alcance xeográfico do dano ambiental que se regula (local, rexional ou global), e non a natureza espacial do problema ambiental (incidencia uniforme ou non). Así, a equivalencia fiscal debe atribuír a xestión ás xurisdicións onde se esgotan os beneficios relacionados co ben ambiental que se pretende protexer (Olson, 1969) e polo tanto, a xestión do dano causado polas emisións debería recaer nunha administración de ámbito internacional ${ }^{5}$. Porén, a dificultade de acadar acordos limita a posibilidade de actuar a nivel internacional, e transfire aos países a responsabilidade de intervir.

A formulación de Kneese (1971) suxire que pode ser desexable definir un nivel mínimo central para a fiscalidade ambiental que garanta unha calidade aceptable en todo o territorio, permitindo ás xurisdicións subcentrais establecer niveis superiores. Este é o caso das emisións, onde pode haber preferencias dispares nos estándares de calidade ambiental no ámbito rexional, malia que ao se tratar dun efecto externo negativo estarían

\footnotetext{
1 NOx e SOx asocíanse principalmente ás emisións procedentes das centrais térmicas.

2 Segundo a análise de Gago et al. (2004), a capacidade recadadora do tributo en Galicia é limitada "obtendo case un $70 \%$ dos seus recursos dun único suxeito pasivo", situación que se pode extender a outras comunidades autónomas como, por exemplo, Aragón.

3 Para máis información, consultar: http:// www2.oecd.org/ ecoinst/ queries/

4 En España, a primeira fase do proceso de descentralización estivo marcada por un aumento do gasto nas administracións subcentrais que non se correspondeu cunha mellora dos recursos tributarios propios. Como consecuencia, o sistema de financiamento autonómico asentábase sobre o mecanismo das transferencias intergobernamentais. As últimas reformas do sistema potenciaron os instrumentos fiscais de carácter autonómico, mellorando a corresponsabilidade fiscal.

5Para o SOx, o efecto está máis localizado e o seu control, segundo este criterio, debe recaer sobre unha administración local.
} 
implicados outros territorios. Nesta liña, Oates (1996) propón atribuír á administración central a responsabilidade de gravar bases impoñibles móbiles e ás subcentrais "relativamente inamobibles", deste xeito, elúdese o risco de competencia fiscal.

Porén, outros autores fan fincapé na necesidade de ter en conta a disparidade xeográfica das preferencias, que desprazaría a xestión cara ás administracións subcentrais. Peltzman e Tideman (1972) apuntan a que calquera aproximación de carácter homoxéneo é ineficiente. O óptimo daríase só cando as xurisdicións adoptasen tipos impositivos diferentes, que levasen a niveis de emisións diferentes en función das preferencias territoriais dispares. De Roo e Miller, (1997), Lowe e Murdoch, (2003) e Nilsson et al. (2009) afirman que a fiscalidade vencella ás administracións subcentrais satisfai de forma máis axeitada ás preferencias territoriais e favorece a resolución de problemas específicos. Porén, dende esta perspectiva elúdese a realidade extraterritorial do problema e a solución convértese nunha suma de solucións parciais. En definitiva e atendendo ao criterio de Olson (1969), parece evidente que se o alcance do dano ambiental rebasa as fronteiras rexionais e require unha medida a nivel nacional, a solución poderíase implementar a nivel central e complementarse dende as autonomías, a través de tipos de gravame distintos.

En canto á literatura empírica que avalía o impacto fiscal sobre as emisións, destacamos o traballo de Larsen e Nesbakken (1996) como unha das primeiras aportacións que inclúe a fiscalidade ambiental. Os seus resultados apuntan á existencia dun impacto significativo sobre a contaminación do Imposto sobre o $\mathrm{CO}_{2}$ e o $\mathrm{SO}_{2}$. Porén, a intensidade do efecto fiscal varía en función da fonte de emisión. Máis adiante, Bruvoll e Larsen (2004) analizan de novo o efecto da política fiscal noruega ampliando o período de estudo. Os autores confirman a súa efectividade, malia que a súa capacidade de reducir a contaminación se sitúa por debaixo do esperado.

Para Francia, Millock e Nauges (2003) estudan a efectividade do Imposto sobre a contaminación atmosférica, entre 1990 e 1999, empregando unha base de datos de 226 instalacións industriais. Os autores cuestionan a eficacia da política fiscal, e suxiren unha reforma tributaria que inclúa subsidios á redución da contaminación para incentivar de forma máis efectiva o cambio de conducta dos axentes económicos.

Recentemente e dentro do marco institucional, destacamos o informe do Nordic Council (2006) que cuantificou as caídas nas emisións de dióxido de carbono en Finlandia e Dinamarca nun 7\% e 5\%, respectivamente, dende a implantación das medidas fiscais a principios dos anos 90 . Xunto a iso, as emisións de dióxido de carbono reduciranse de maneira significativa, ata acadar un $14 \%$ en Noruega, que se situaba no $21 \%$ para as plantas de produción de enerxía. No devandito documento, tamén se estimou o efecto do Imposto sobre a enerxía e o $\mathrm{CO}_{2}$ en Suecia, que acada os 0.5 millóns de toneladas de redución anual para o dióxido de carbono.

Continuando no ámbito institucional, atopamos o documento publicado pola OCDE (2006), onde se avalía o impacto dun conxunto de medidas fiscais aprobadas a finais dos anos 90 en Alemaña. A reforma do sistema tributario supuxera, segundo o informe, unha redución diferencial de entre o $2 \%$ e o $3 \%$ con respecto a un escenario business as usual.

Por último, podemos consultar unha ampla revisión da literatura na meta-análise de Baranzini e Carattini (2013), que falan do efecto ex-post dos impostos sobre as emisións. A conclusión principal deste traballo pódese sintetizar na seguinte afirmación "a política climática debe ser considerada dende unha perspectiva integral". Así, os autores recomendan unha política fiscal que se enmarque nunha reforma máis ampla e que permita compensar algúns efectos potencialmente "indesexables" da implantación dos impostos ambientais. 
Na literatura para España, aparecen diferentes propostas de aplicación e reforma fiscal sobre as emisións. Un detallado resumo das mesmas atópase na meta-análise de Gago et al. (2014), onde destacan as aportacións de Labandeira e Labeaga (1999, 2000, 2002), Gallastegui et al. (2011) e González-Eguino (2011), entre outros.

Porén, dada a implementación recente da tributación sobre emisións, non contamos con traballos que avalíen a súa efectividade. Este desinterese a nivel académico é consecuencia do aínda máis escaso interese político, que favoreceu a aparición de tributos cunha limitada capacidade recadadora ${ }^{6}$. Nembargantes, cando se incorporaron ao sistema, parece interesante formular unha avaliación dos seus resultados.

\section{3.- Datos e metodoloxía}

Para a análise empírica, seleccionamos dúas mostras de 100 instalacións industriais de tamaño medio e grande, das que se dispón dun volume elevado de información sobre as súas emisións. Así mesmo, cubren unha parte moi importante da contaminación e do pago tributario. Isto se debe a que os elevados mínimos exentos e algúns supostos de non subxeición limitan o número de contribuíntes de forma significativa, especialmente en Galicia e Castela-A Mancha (Gago et al. 2002).

A primeira mostra recolle o fluxo de emisións anuais de dióxido de carbono. A devandita substancia de orixe natural non supón un risco ambiental en si mesma, pero o seu exceso de concentración na atmosfera favorece o quentamento global e acelera o cambio climático. A segunda base de datos está composta polas emisións anuais de óxidos de nitróxeno e de azufre, gravados nas cinco autonomías que implementan impostos directos sobre a contaminación (Andalucía, Aragón, Castela A-Mancha, Galicia e Murcia).

A información nos dous casos obtense do Rexistro Estatal de Emisións e Fontes Contaminantes (EPER), e abrangue dende 2001 a 2011. Este período inclúe a posta en marcha de todos os tributos autonómicos, agás o de Galicia (1996). A porcentaxe sobre os totais das mostraxes das instalacións que pertencen a cada sector (táboa A.1) e a súa distribución xeográfica por autonomías (gráfico A.1) pódense consultar no anexo 1 deste traballo, así como os principais estatísticos descritivos das variables empregadas no modelo empírico (táboa A.2).

Unha vez definida a composición da mostra, imos presentar os modelos empíricos que imos implementar para investigar a efectividade ambiental das medidas fiscais. Como se mencionou anteriormente, para poder avaliar de maneira axeitada o impacto das medidas de corrección do comportamento dos axentes propóñense dous modelos. A forma funcional do primeiro, queda do seguinte xeito:

$$
\begin{aligned}
\ln \left(\mathrm{CO}_{2}\right)_{\mathrm{jt}}=\mathrm{b}_{0}+ & \mathrm{b}_{1} \ln (\mathrm{IE})_{\mathrm{jt}}+\mathrm{b}_{2} \ln (\mathrm{A})_{\mathrm{jt}}+\mathrm{b}_{3}(\mathrm{P})_{\mathrm{jt}}+\mathrm{b}_{4} \mathrm{~S}_{1} \cdot \ln (\mathrm{T})_{\mathrm{jt}-1}+[1] \\
& \mathrm{b}_{5} \mathrm{~S}_{2} \cdot \ln (\mathrm{T})_{\mathrm{jt}-1}++\mathrm{b}_{6} \mathrm{~S}_{3} \cdot \ln (\mathrm{T})_{\mathrm{jt}-1}+\mathrm{b}_{7} \mathrm{~S}_{4} \cdot \ln (\mathrm{T})_{\mathrm{jt}-1}+ \\
& \mathrm{b}_{8} \mathrm{~S}_{5} \cdot \ln (\mathrm{T})_{\mathrm{jt}-1}+\varepsilon_{\mathrm{jt}}
\end{aligned}
$$

Onde "j" é o índice de cada instalación e "t" é o período temporal. A variable independente obtense aplicando logaritmos naturais ás emisións anuais de dióxido de carbono. Desta forma, evítanse os problemas derivados da heteroscedasticidade e heteroxeneidade no tamaño das instalacións que compoñen as mostras.

En primeiro lugar, para coñecer o impacto da fiscalidade sobre as emisións de dióxido de carbono provenientes de instalacións situadas en Andalucía e Aragón (30\% do total da mostra), incorporouse a variable $\left(\ln _{\mathrm{t}-1}\right)$. O cálculo realízase aplicando os tipos de gravame ás emisións asignadas a cada instalación, xa que se a instalación acode ao mercado de permisos, a cantidade adquirida queda exenta para evitar o pagamento por

${ }^{6}$ A información pódese consultar na páxina do Ministerio de Facenda: http://www.minhap.gob.es/ esES/Areas\%20Tematicas/ Financiacion\%20Autonomica/ Paginas/tributospropiosautonomicos.aspx 
duplicado. No caso contrario, se a instalación emite por debaixo do nivel asignado, tribútase polo total emitido ${ }^{7}$. Así mesmo, co fin de contrastar a existencia de diferenzas significativas no impacto fiscal por subsectores de actividade industrial, engadíronse cinco variables ficticias (unha por subsector), que se multiplican pola cota tributaria $\left(\mathrm{S}_{1}, \mathrm{~S}_{2}\right.$, $\left.\mathrm{S}_{3}, \mathrm{~S}_{4}, \mathrm{~S}_{5}\right)$.

Para a selección do resto de variables independentes, tívose en conta o traballo Grossman e Krueger (1991) e máis recentemente, de Stern (2004), onde se afirma que a evolución do dano ambiental depende de tres factores. O primeiro deles, denominado efecto escala, recolle o impacto do nivel de produción sobre as emisións baixo a hipótese de que a máis produción, máis contaminación. Para medir o devandito efecto, introducimos o logaritmo dos ingresos por explotación (IE). En segundo lugar, o autor identifica a tecnoloxía como un elemento fundamental á hora de explicar os cambios na contaminación. De acordo co criterio Cole et al. (2008) e Le Lannier (2010), o logaritmo da antigüidade (A) é unha aproximación determinista ao concepto de crecemento exóxeno en investimento tecnolóxico. Polo tanto, canto máis antiga é a compañía, máis intenso é o control das emisións a través dos seus investimentos en investigación e desenvolvemento tecnolóxico. Nos dous casos, os datos proveñen da base de datos do Sistema de Análise de Balances Ibéricos (SABI).

A presente investigación realízase dende una perspectiva microeconómica, e por iso, omítese o efecto substitución do output descrito por Grossman e Krueger (1991) e Stern (2004). O devandito efecto ten lugar cando os factores produtivos móvense cara sectores menos contaminantes nunha etapa de crecemento económico consolidado (da industria aos servizos), e cuxa análise se circunscribe exclusivamente á contorna macro.

Por outra banda, optamos por introducir unha variable ficticia que recolle o impacto da lexislación europea sobre intercambio de permisos de dióxido de carbono (p). A súa posta en marcha tivo lugar en 2005 co primeiro Plan Nacional de Asignación (20052007)8. O 86\% das instalacións que forman a mostra foron incluídas nesta primeira etapa, namentres que o segundo plan (2008-2011) cubriu o 89\% do total. O 11\% restante é a mostra de control formada polas instalacións que non estiveron incluídas en ningún dos dous plans. Finalmente, imos implementar o modelo [2] para medir o impacto fiscal a nivel agregado:

$$
\ln \left(\mathrm{CO}_{2}\right)_{\mathrm{jt}}=\mathrm{b}_{0}+\mathrm{b}_{1} \ln (\mathrm{IE})_{\mathrm{jt}}+\mathrm{b}_{2} \ln (\mathrm{A})_{\mathrm{jt}}+\mathrm{b}_{3}(\mathrm{P})_{\mathrm{jt}}+\mathrm{b}_{4} \ln (\mathrm{T})_{\mathrm{jt}-1}+\varepsilon_{\mathrm{jt}}
$$

Para os óxidos de nitróxeno e de azufre, replicamos o modelo [1] ampliando a variable fiscal para todas as instalacións industriais suxeitas ao tributo, o que representa 0 $47 \%$ da mostra. Asemade, excluímos os permisos de emisión (p) que non se aplican para ámbalas dúas substancias. Desta forma, o modelo queda:

$$
\begin{gathered}
\ln (\mathrm{NOx}+\mathrm{SOx})_{\mathrm{jt}}=\mathrm{b}_{0}+\mathrm{b}_{1} \ln (\mathrm{IE})_{\mathrm{jt}}+\mathrm{b}_{2} \ln (\mathrm{A})_{\mathrm{jt}}+\mathrm{b}_{3} \mathrm{~S}_{1} \cdot \ln (\mathrm{T})_{\mathrm{jt}-1}+\mathrm{b}_{4} \mathrm{~S}_{2} \cdot \ln (\mathrm{T})_{\mathrm{jt}-1}+\mathrm{b}_{5} \mathrm{~S}_{3} \cdot \ln (\mathrm{T})_{\mathrm{jt}-1}+ \\
\mathrm{b}_{6} \mathrm{~S}_{4} \cdot \ln (\mathrm{T})_{\mathrm{jt}-1}+\mathrm{b}_{7} \mathrm{~S}_{5} \cdot \ln (\mathrm{T})_{\mathrm{jt}-1}+\varepsilon_{\mathrm{jt}}
\end{gathered}
$$

Namentres que o efecto fiscal agregado analízase no seguinte modelo:

$$
\begin{gathered}
\ln (\mathrm{NOx}+\mathrm{SOx})_{\mathrm{jt}}=\mathrm{b}_{0}+\mathrm{b}_{1} \ln (\mathrm{IE})_{\mathrm{jt}}+\mathrm{b}_{2} \ln (\mathrm{A})_{\mathrm{jt}}+\mathrm{b}_{3} \ln (\mathrm{T})_{\mathrm{jt}-1} \\
+\varepsilon_{\mathrm{jt}}
\end{gathered}
$$

\footnotetext{
${ }^{7}$ A información extráese dos Plans Nacionais de Asignación, que publica o Ministerio de Agricultura e do EPER.

8 Decisión da Comisión 2000/479/EC. Nas dúas primeiras fases, os gobernos nacionais asignaban os dereitos comerciables, namentres que a institución comunitaria se limitaba a establecer os límites para cada Estado. Dende 2013, esta asignación realízase no marco das institucións comunitarias.
} 


\section{4.- Resultados}

A estimación paramétrica dos modelos [1], [2], [3] y [4] levouse a cabo a través da metodoloxía de mínimos cadrados xeneralizados para datos de panel, controlando o incumprimento das hipóteses de homoscedasticidade (Test Lr) en todos os casos e na autocorrelación (Test de Wooldridge) en [3] e [4] . Os resultados dos tests amósanse na parte inferior da táboa 3.

Os resultados dos modelos [1] e [2] amósannos a inexistencia dun efecto fiscal significativo sobre as emisións de dióxido de carbono, tanto a nivel sectorial como agregado. O resultado repítese nas estimacións das ecuacións [3] y [4], polo que podemos concluír que a tributación ambiental autonómica tampouco é unha ferramenta efectiva para o control e prevención da emisión de substancias que causan a choiva ácida. A nivel desagregado, non se aprecian diferenzas substanciais con respecto ao resultado xeral. En definitiva, os estimadores determinan que o efecto fiscal non é significativo en ningún sector produtivo.

Isto implica que, segundo a evidencia empírica considerada, a fiscalidade ambiental introducida polas comunidades autónomas non é capaz de incentivar un cambio de conducta no comportamento dos axentes económicos que emiten dióxido de carbono, nin tampouco entre aqueles que emiten óxidos de nitróxeno e azufre. A estimación das elasticidades permítenos comprobar a reducida intensidade da política fiscal, especialmente se comparamos os devanditos resultados cos obtidos por Millock e Nauges (2003) para Francia. Nese traballo, a elasticidade acadaba a cifra de 2'18 dependendo da substancia contaminante analizada, namentres que no noso caso, en ningún dos modelos se proxecta un resultado por enriba do 1\%, sendo o do modelo [2], o máis elevado cun 0’006.

Táboa 3: Resultados xerais

\begin{tabular}{|c|c|c|c|c|}
\hline & [1] & [2] & [3] & [4] \\
\hline Cons. & $\begin{array}{c}11.07887^{* * *} \\
(14.30)\end{array}$ & $\begin{array}{c}11.17473^{* * * *} \\
(14.33)\end{array}$ & $\begin{array}{c}3.948941^{* * *} \\
(16.27)\end{array}$ & $\begin{array}{c}3.904355^{* * *} \\
(16.23)\end{array}$ \\
\hline $\ln (\mathrm{IE})$ & $\begin{array}{c}0.2022584^{* * *} \\
(3.63)\end{array}$ & $\begin{array}{c}0.1961158^{* * *} \\
(3.51)\end{array}$ & $\begin{array}{c}0.4324232^{* * *} \\
(9.95)\end{array}$ & $\begin{array}{c}0.4336984^{* * *} \\
(10.02)\end{array}$ \\
\hline $\operatorname{Tr}$ & $\begin{array}{c}-0.010695^{\text {**** }} \\
(-3.96)\end{array}$ & $\begin{array}{c}-0.0111115^{* * *} \\
(-4.05)\end{array}$ & $\begin{array}{c}-0.0458926^{* * *} \\
(-3.40)\end{array}$ & $\begin{array}{c}-0.0450526^{* * *} \\
(-3.35)\end{array}$ \\
\hline $\mathrm{p}$ & $\begin{array}{c}-0.1075143^{* *} \\
(-2.32)\end{array}$ & $\begin{array}{c}-0.0993777^{* *} \\
(-2.13)\end{array}$ & - & 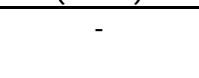 \\
\hline $\ln (T)_{(t-1)}$ & - & $\begin{array}{c}-0.0045917 \\
(-0.79)\end{array}$ & - & $\begin{array}{c}-0.0064831 \\
(-0.69)\end{array}$ \\
\hline Térmica $\left(\mathrm{S}_{1}\right)$ & $\begin{array}{c}-0.0108852 \\
(-1.19)\end{array}$ & - & $\begin{array}{c}-0.0041512 \\
(-0.24)\end{array}$ & \\
\hline Refinaría $\left(\mathrm{S}_{2}\right)$ & $\begin{array}{c}0.0001511 \\
(0.03)\end{array}$ & - & $\begin{array}{c}-0.018952 \\
(-0.79)\end{array}$ & \\
\hline Química $\left(\mathrm{S}_{3}\right)$ & $\begin{array}{c}-0.0021927 \\
(-0.28)\end{array}$ & - & $\begin{array}{c}0.0061388 \\
(0.21)\end{array}$ & \\
\hline Cemento $\left(\mathrm{S}_{4}\right)$ & $\begin{array}{c}0.0026188 \\
(0.43)\end{array}$ & - & $\begin{array}{c}-0.0101972 \\
(-0.60)\end{array}$ & \\
\hline Siderurxia $\left(\mathrm{S}_{5}\right)$ & $\begin{array}{c}-0.004897 \\
(-0.89)\end{array}$ & - & $\begin{array}{c}0.052192 \\
(0.68)\end{array}$ & \\
\hline $\mathrm{R}^{2}$ & 0.1524 & 0.1497 & 0.1199 & 0.1226 \\
\hline Wooldridge & 0.4576 & 0.2475 & 0.0001 & 0.0260 \\
\hline Test LR & 0.0000 & 0.0000 & 0.0000 & 0.0000 \\
\hline
\end{tabular}

Nota: ${ }^{*}$ Significatividade ao $10 \%{ }^{* *}$ Significatividade ao $5 \% .{ }^{* * *}$ Significatividade ao $1 \%$. 
Da Táboa 3 despréndese que o deseño tributario, caracterizado pola limitada contía dos tipos de gravame (táboas 1 e 2), e o escaso número de contribuíntes, impediu obter uns resultados significativos. Así mesmo, a natureza rexional da tributación, que trata de internalizar un efecto externo que supera por moito os límites xurisdicionais, dificulta aínda máis a obtención dos beneficios ambientais buscados. En definitiva, trátase dun instrumento fiscal ineficaz, e pouco ambicioso a nivel ambiental, que require unha reforma tributaria en profundidade para garantir un cambio significativo na conducta dos axentes económicos.

Con respecto ao resto de variables independentes, no caso dos ingresos por explotación (IE), dende un plano teórico, asocíase unha maior actividade produtiva cun incremento nos niveis de contaminación nun contexto de cambio tecnolóxico estacionario, que recolle o efecto escala definido por Grossman e Krueger (1991) e Stern (2004). En ámbalas dúas mostras, o resultado empírico coincide coa formulación descrita. Para 0 impacto da tecnoloxía, a estimación dá un resultado negativo e significativo, o que é reflexo da capacidade que ten a innovación para modificar o proceso produtivo e mitigar o dano ambiental, como se menciona en diferentes informes institucionais (Axencia de Protección Ambiental, OCDE, Unión Europea...) e investigacións académicas como, por exemplo, en Picazo-Tadeo e García-Reche (2005).

En canto á variable ficticia que mide o impacto da aplicación do sistema de intercambio de emisións (p), o parámetro estimado é negativo e significativo sustentando a hipótese inicial. Isto coincide ademais, con algúns traballos empíricos como Abrell et al. (2011), onde os autores atopan evidencia do impacto do sistema de intercambio, especialmente na industria de minerais non metálicos e na de metais básicos. Nunha liña similar, Martin et al. (2012) cuantifican o impacto medio da primeira fase de asignación nun $3 \%$. Con respecto á segunda fase, obteñen que o impacto durante o primeiro ano é moi significativo e que, a partir do segundo, a redución de emisións deriva en maior medida da crise económica. Recentemente, Laing et al. (2013), afirmaban que o sistema de intercambio fora efectivo nas dúas fases, pero que o exceso de oferta da primeira fase, e a crise económica durante a segunda, limitaran a devandita efectividade. Finalmente, Fernández et al. (2013) obteñen que o sistema de permisos de emisión foi unha ferramenta eficaz na redución no fluxo anual de emisións contaminantes en España.

Por tanto, parece que existe evidencia suficiente para afirmar que o sistema de intercambio de permisos estimula certa redución da contaminación. O éxito deste instrumento pode estar asociado a que o sistema se aplica como unha medida internacional de control das emisións, o que permite afrontar un problema que traspasa as fronteiras nacionais de maneira coordinada.

\section{5.- Conclusións e implicacións políticas}

Reducir o volume de emisións contaminantes provenientes da produción industrial é un dos desafíos na loita contra o cambio climático. Para poder afrontalo, requírese un maior compromiso ambiental por parte dos axentes económicos que só é posible cunha axeitada política de incentivos. Un dos instrumentos políticos máis frecuentes é a tributación, que permite internalizar o efecto negativo da contaminación a través dos cambios nos procesos produtivos e, simultaneamente, obter ingresos tributarios. Porén, a súa efectividade depende de que se estableza unha estratexia coordinada e un diseño fiscal ambicioso.

Neste senso, a intervención das administracións públicas en España limitouse á aprobación de cinco gravames autonómicos que ademais, adoecen dunha estrutura tributaria verdadeiramente incentivadora. Este feito percébese ao observar que fiscalizan as emisións dunhas poucas instalacións industriais de gran tamaño, proxectando a imaxe 
de que a finalidade é máis recadadora ca ambiental, e que prevalece o fin de minimizar os custos de administración. Por este motivo, a tributación autonómica espertou un interese mínimo na literatura científica.

En calquera caso, a posta en marcha da política fiscal sobre emisións a nivel rexional supón a primeira achega do noso sistema tributario ao de outros países europeos. Por iso, e dado que pasou máis dunha década dende a aprobación dos primeiros tributos, tratamos de analizar empiricamente a efectividade das cinco figuras tributarias sobre as emisións de dióxido de carbono, óxido de nitróxeno e óxido de azufre, para unha mostra de 100 instalacións industriais.

Á vista dos resultados obtidos, podemos afirmar que a implementación dos devanditos tributos tiveron un efecto moi limitado. Neste contexto, parece evidente que se require unha reforma en profundidade da tributación sobre emisións en España, baseada en tres criterios: redefinición da administración competente en materia de emisións; adecuación dos tipos de gravame ao dano ambiental; e ampliación do número de contribuíntes.

Con respecto ao primeiro criterio, e tendo en conta a natureza global da contaminación atmosférica (agás para o caso do $\mathrm{SO}_{2}$, cuxa incidencia é local), é recomendable unha solución internacional. Porén, a harmonización europea da política fiscal é difícil de acadar e, polo tanto, a solución pasa pola implicación dos diferentes gobernos centrais a nivel europeo á hora de implementar a tributación ambiental a nivel nacional. Neste ámbito, unha medida de carácter internacional como o sistema de intercambio de permisos ten un papel fundamental, grazas a que favorece a coordinación transfronteiriza da política de control de emisións de dióxido de carbono, sen importar a localización da actividade contaminante. Asemade, o propio mecanismo de compra-venda de permisos supón un incentivo para reducir as emisións e, deste xeito, introduce unha solución de mercado a través do intercambio de dereitos.

Atendendo ao segundo criterio, os tipos de gravame deben posibilitar a internalización do dano ambiental causado polas emisións, e xerar un incentivo á mellora no comportamento ambiental das empresas. Á vista das elasticidades obtidas, no deseño da nova política tributaria debe primar a aplicación de tipos máis elevados que se axusten á magnitude do problema que tratan de corrixir. Finalmente, a ampliación do número de contribuíntes é un elemento esencial á hora de reforzar o incentivo á descontaminación e, en xeral, para a mellora do deseño tributario. Finalmente, e a pesar de que as devanditas medidas supoñen certa centralización da política ambiental, as comunidades autónomas poderían xogar un papel activo na fixación dos tipos de gravame e bonificacións fiscais de carácter ambiental, sempre e cando quede garantido un mínimo común de protección en todo o territorio nacional.

\section{Referencias bibliográficas}

Abrell, J.; Ndoye Faye, A. \& Zachmann, G. (2011): "Assessing the impact of the EU ETS using firm level data" Bruegel working paper,8.

André F.; Cardenete, M.A. \& Velázquez, E. (2005): Performing an environmental tax reform in a regional economy. A computable general equilibrium approach. The Annals of Regional Science, 39(2), pp. 375-392.

Baranzini, A. \& Carattini, S. (2013). Taxation of emissions of greenhouse gases: The environmental impacts of carbon taxes. Global Environmental Change. Bill Freedman (Ed.), SpringerReference.

Bosquet, B. (2000): "Environmental tax reform: does it work? A survey of the empirical evidence". Ecological economics, 34(1), pp. 19-32. 
Bruvoll, A. \& Larsen, B.M. (2004): “Greenhouse gas emissions in Norway: do carbon taxes work?” Energy Policy 32, pp. 493-505.

Cole, M. A.; Elliott, R. J., \& Wu, S. (2008): "Industrial activity and the environment in China: An industry-level analysis". China Economic Review, 19(3), pp. 393-408.

Commission Decision 2000/ 479/ EC of 17 July 2000 on the implementation of a European Pollutant Emission Register (EPER) according to Article 15 of Council Directive 96/61/ EC concerning integrated pollution prevention and control (IPPC).

Conefrey, T.; Gerald, J.; Valeri, L. \& Tol, R. (2008): "The impact of a carbon tax on economic growth and carbon dioxide emissions in Ireland". ESRI working paper, 251.

De Roo G. \& Miller D, 1997, "Transitions in Dutch environmental planning: new solutions for integrating spatial and environmental policies" Environment and Planning B: Planning and Design 24 (3), pp. 427 - 436.

Fernández, Y.; Fernández, Ma․ ; González, D. \& Olmedillas, B. (2013): Intensidad energética y emisiones de $\mathrm{CO}_{2}$ : un análisis para Castilla y León y España*. Reunión de Estudios Regionales.

Gago, A. \& Labandeira, X. (1997): "La imposición ambiental: Fundamentos, Tipología Comparada y Experiencias en la OCDE y en España". Hacienda Pública Española, 141/ 142, pp. 193-219.

Gago, A.; Labandeira, X. \& Rodríguez, M. (2002): "La Práctica de la Imposición Ambiental y de las Reformas Fiscales Verdes", en Gago, A. \& Labandeira, X. (dirs) Energía, Fiscalidad y Medio Ambiente en España. Instituto de Estudios Fiscales, Madrid.

Gago, A.; Labandeira, X. \& Rodríguez, M. (2004): “Evidencia Empírica Internacional sobre los Dividendos de la Imposición Ambiental", en BUÑUEL, M. (editor): Fiscalidad Ambiental, Civitas, Madrid.

Gago, A.; Villot, X. L. \& López, X. (2014). Impuestos energético-ambientales en España. Energía de hoy. com, (6), pp. 62-65.

Gallastegui, M.C.; González-Eguino, M. \& Galarraga, I.(2011): "Cost effectiveness of a combination of instruments for global warming: a quantitative approach for Spain". SERIEs, 58.

González-Eguino, M. (2011): "The importance of the design of market -based instruments for $\mathrm{CO}_{2}$ mitigation: An AGE analysis for Spain”. Ecological Economics, 70(12), pp. 22922302.

Grossman, G. \& Krueger, A. (1991): "Environmental impacts of a north American free trade agreement”, Working paper no 3914, National Bureau of Economic Research. Cambridge, MA, November.

EPER. Ministry of Agriculture and Environment. <www.prtr.es>.

Kneese, A.V. (1971): "Environmental Pollution: Economics and Policy", The American Economic Review 61(2), pp. 153-66.

Labandeira, X. \& Labeaga, J. (1999): “Combining Input-Output and Microsimulation to Assess the Effects of Carbon Taxation on Spanish Households". Fiscal Studies 20(3), pp. 303-318.

Labandeira, X.\& Labeaga, J.M. (2000): "Efectos de un impuesto sobre las emisiones de $\mathrm{SO}_{2}$ del sector eléctrico". Revista de Economía Aplicada, 22, pp. 5-32

Labandeira, X \& Labeaga. J.M. (2002): "Estimation and Control of Spanish Energy-Related $\mathrm{CO}_{2}$ Emissions: An Input-Output Approach". Energy Policy, 30 (2002), pp. 597-611.

Labandeira, X.; Labeaga, J.M. \& Rodríguez, M. (2005): “Análisis de eficiencia y equidad de una reforma fiscal verde en España”. Cuadernos económicos de ICE, 70, pp. 207-225. 
Laing, T.; Sato, M.; Grubb, M. \& Comberti, C. (2013): "Assessing the effectiveness of the EU emissions trading system". Working Paper 126, Centre for Climate Change Economics and Policy.

Larsen, B.D. \& Nesbakken, R. (1997): "Norwegian Emissions of CO2 1987-1994: A Study of Some Effects of the C02 Tax". Environmental and Resource Economics 9, pp. 275-290.

Le Lannier, A. (2010): "Enforcement of Yardstick Contracts \& Consistency in Performance Rankings: An Application to the Water Industry in England and Wales". Discussion Paper Series.

Lowe P. \& Murdoch J. (2003): "Mediating the 'national' and the 'local' in the environmental policy process: a case study of the CPRE" Environment and Planning C: Government and Policy 21(5), pp. $761-778$.

Martin, R.; Muûls, M.; \& Wagner, U. (2012): "An evidence review of the EU Emissions Trading System, focussing on effectiveness of the system in driving industrial abatement". Department of Eenrgy and Climate Change.

Millock, K. \& Nauges, C. (2003): The French Tax on Air Pollution: Some Preliminary Results on its Effectiveness. CLIM - Climate Change Modelling and Policy.

National Statistics Institute. $<w w w . i n e . e s>$.

Nilsson, M. Eklund, M. \& Tyskeng, S. (2009): "Environmental integration and policy implementation: competing governance modes in waste management decision making". Environment and Planning C: Government and Policy 27(1), pp.1-18.

Nordic Council, (2006): "The use of economic instruments in environmental policy in the Nordic and Baltic countries 2001-2005". Copenhagen, Denmark,

Oates, W.E. (1996): "The invisible hand in the public sector: Interjurisdictional competition in theory and practice".

Olson, M. (1969): "The Principle of "Fiscal Equivalence", The division of responsibilities among different levels of government, American Economic Review 59 (2),pp. 479-487.

OCDE. The OECD/ EEA database on instruments used for environmental policy and natural resources management. Base de datos disponible en http:/ stats.oecd.org/

OECD (2006): "The Political Economy of Environmentally Related Taxes." Paris.

Patuelli, R.; Nijkamp, P. \& Pels, E. (2005): "Environmental tax reform and the double dividend: A meta-analytical performance assessment". Ecological Economics, 55(4), pp. 564-583.

Peltzman, S. \& Tideman, T. (1972): "Local Versus National Pollution Control: Note", American Economic Review, 62, pp. 959-963.

Picazo-Tadeo A. \& García-Reche A. (2005): "What makes environmental performance differ between firms? Empirical evidence from the Spanish tile industry". Environment and Planning A. 39, pp. 2232 - 2247.

Pigou, A.C. (1920): The Economics of Welfare. Macmillan and Co. Londres.

Remuzgo, L. \& Sarabia, J. M. (2013): “Desigualdad en la distribución mundial de emisiones de CO2 por sectores: Descomposición y estudio de sensibilidad". Estudios de Economía Aplicada, 31,pp. 65-92

Rodríguez, M. (2002): "Reforma fiscal verde y doble dividendo: una revisión de la evidencia empírica". Papeles de trabajo del Instituto de Estudios Fiscales. Serie economía, 27, pp. 7-26.

Theil, H. (1967): Economics and information theory (Vol. 7). Amsterdam: North-Holland

Anexo on line: https:/ / ideas.repec.org/ s/ sdo/ regaec.html

Revista Galega de Economía: http:/ / www.usc.es/ econo/ RGE/ benvidag.htm 